\title{
RECENSÕES SOBRE EDUCAÇÃO E DEMOCRACIA ÉTICA NA OBRA DE MÁRIO VIEIRA DE MELLO
}

Artur José Renda Vitorino*

RESUMO: O objetivo deste texto é examinar o que foi exposto, em linhas gerais, por Mário Vieira de Mello (1912-2006) e denominado por ele de projeto de democracia ética (derivada essencialmente de estruturas de Cultura), numa contraposição à democracia igualitária (derivada essencialmente de estruturas de Poder). Em outros termos, a liberdade como autodeterminação da pessoa humana em contraposição à liberdade como faculdade de escolha, pois o reconhecimento imediato à liberdade como autodeterminação da pessoa é a chave para o problema das relações entre a liberdade da pessoa e o interesse do Estado e da Sociedade. Para esse autor, a educação poderá oferecer o seu contributo para o problema da democracia, à medida que conseguir enriquecer seu conteúdo com verdadeiras ideias de Cultura. A ideia de liberdade interior é um desses elementos que a educação pode oferecer a qualquer sistema democrático. Palavras-Chave: Educação. Democracia Ética. Razão. Liberdade. Mário Vieira de Mello.

\footnotetext{
* Doutor em História pela Universidade Estadual de Campinas (UNICAMP) e Professor do Programa de Pós-Graduação em Educação da Pontifícia Universidade Católica de Campinas (PUC-CAMPINAS). Email: arturvitorino@uol.com.br
} 


\title{
REVIEWS ON EDUCATION AND ETHICAL DEMOCRACY FROM MÁRIO VIEIRA DE MELLO WORKS
}

\begin{abstract}
This paper aim to examine what has been brought to light, in general, by Mário Vieira de Mello (1912-2006), and called by him as ethical democracy project (extracted mainly from Cultural structures), in contrast to egalitarian democracy (derived mainly from Power structures). Furthermore, freedom as self-determination for human person as an individual by contrast to freedom as the right for choice, since the immediate freedom recognition as self-determination of the person is the key to relationship problem among human freedom not only to the State interest as well to Society. Accordingly this author, education may provide great contribution to democracy problem, moreover enriches the content to achieve true ideas of Culture. Broadly speaking, the inner freedom idea is one of those elements which education may be the conveyance to any democratic system.
\end{abstract}

Keywords: Education. Ethical Democracy. Reason. Freedom. Mário Vieira de Mello.

\section{INTRODUÇÃO}

Frequentemente mencionada nos estudos sobre a democracia, a ideia de igualdade, para Mário Vieira de Mello (1912-2006), é uma forma da ideia de justiça que surgiu no momento histórico em que a Cultura se divorciou do Poder, causando assim a transformação na Constituição do Estado. Desse modo, desde as civilizações do antigo Oriente Próximo, a ideia de igualdade se relacionava mais com ideia de Poder do que com a ideia de Cultura. Da perspectiva do Poder, então, a ideia de igualdade prevalece sobre a ideia de liberdade. Porque derivada da ideia de igualdade, a liberdade é assim denominada de liberdade externa: como, em minha individualidade, sou igual ao outro indivíduo, tenho, por isso, poder e liberdade de agir e fazer as coisas tal como ele. Os homens são iguais e livres a fim de ter o poder de fazer livre e igualmente as mesmas coisas.

Por outro lado, para Vieira de Mello, existe também uma ideia de liberdade que não deriva da noção de igualdade embora derive da ideia de justiça. Mas justiça aqui é um conceito mais complexo do que aquele que fez surgir a ideia de igualdade. Paradoxalmente, aqui justiça parece identificar-se com a noção mesma de desigualdade. Isso porque existem homens que são justos contrariamente ao que acontece com a maioria deles. Esses homens são igualmente livres; conseguem controlar 
suas próprias paixões e instintos e, desse modo, adquirem certo grau de liberdade. Essa espécie de liberdade não outorga poder sobre as coisas ou outros homens, mas oferece ao homem que a possui uma entrada franca no mundo da cultura. À liberdade assim constituída, Vieira de Mello denominou liberdade interior, cuja face interna está associada ao mundo da cultura. Ela pode eventualmente antagonizar sua face externa, associada ao mundo do Poder.

Em geral, os estudos mostram uma evolução histórica do ideal democrático por meio do princípio de uma liberdade global, de uma liberdade não diferenciada, cujo princípio torna-se, por isso, uma ideia perversa justamente porque se apresenta a liberdade como um conceito global, um conceito no qual a liberdade exterior e a liberdade interior não são distinguidas e no qual não há indicação do conflito que possa existir entre elas.

E mesmo quando as investigações alertam para a questão do perigo, elas afirmam no sentido de que a liberdade não deve realizar a sobreposição dela sobre a igualdade, e mesmo vice versa. Para Vieira de Mello, as nossas reflexões precisam, sim, se mirar na hostilidade que existe entre Cultura e Poder, para assim percebermos que essa hostilidade pode se tornar manifesta no próprio centro da ideia de liberdade. Nota-se, ainda, que a paixão pela igualdade é mais forte e prevalece mais do que a paixão pela liberdade; assim como a Estrutura de Poder, pela sua própria natureza, se impõe sobre a Estrutura de Cultura.

Este texto procura apresentar evidências, por meio do estudo das obras de Vieira de Mello, da necessidade de termos uma postura decididamente a favor de ideias de Cultura e sua relação antitética e agônica com as ideias de Poder. Para esse autor, a educação tem como primeira obrigação manter, com nitidez, uma distinção entre o mundo do Poder e o mundo da Cultura, bem como a educação não pode se deixar iludir pela sedução do mundo do Poder. A tarefa da educação, deste modo, é fazer com que prevaleça sempre a prioridade da cultura nas articulações que eventualmente se façam entre esses dois mundos.

A seguir, esses argumentos são desenvolvidos em três seções: a primeira apresenta o filósofo Mário Vieira de Mello, pois ele é pouco visitado nos estudos educacionais, por meio de uma breve biografia e de sua bibliografia; a segunda examina a descoberta da liberdade como problema moral; a terceira argumenta que a expressão máxima da racionalidade na vida humana é a razão como dinâmica pedagógica. A última seção resume as principais conclusões do texto. 
Neste estudo da obra de Mário Vieira de Mello, adotei o princípio da leitura crítica por meio do método de interpretação desenvolvido por Bernard Lonergan (2013[1971], p. 171-196). Para Lonergan (2013, p. 18-19),

\begin{abstract}
método é um esquema normativo de operações recorrentes e inter-relacionadas que produzem resultados cumulativos e progressivos. Temos um método, portanto, quando temos operações distintas; quando cada uma delas se relaciona com as outras; quando o conjunto de relações forma um esquema; quando o esquema é descrito como a maneira correta de executar determinada tarefa; quando as operações que estão de acordo com o esquema podem ser repetidas indefinidamente; e quando os frutos dessa repetição não são repetidos, mas cumulativos e progressivos.
\end{abstract}

Ao definir a expressão método como "um esquema normativo de operações recorrentes e inter-relacionadas que produzem resultados cumulativos", Lonergan avalia que método não é concebido como um conjunto de regras que produz resultados satisfatórios. Os resultados só serão progressivos se houver uma sucessão constante de descobertas, e, do mesmo modo, só serão cumulativos se houver uma síntese de cada intelecção nova com todas as intelecções válidas anteriormente.

Assim, o método interpretativo desenvolvido por Lonergan (2013, p. 171) permitiu a ele afirmar que "a interpretação possui uma finalidade própria e um modo específico de operar", pelo qual um texto pode vir a ser interpretado (usando a terminologia hermenêtica para falar dos princípios da interpretação e exegese para indicar a aplicação desses princípios a uma tarefa específica) por meio das seguintes operações exegéticas básicas: (1) compreender o texto; (2) julgar o quão correto é seu entendimento; e (3) afirmar o que é considerado seu entendimento correto.

A compreensão do texto, por sua vez, possui quatro aspectos principais os quais redundam no ato de compreender, a saber: a) compreender o objeto ao qual o texto se refere; b) compreender as palavras que o texto emprega; c) compreender o autor que empregou tais palavras; e d) chegar a essa conclusão por meio de um processo de aprendizagem e, às vezes, até por meio de uma conversão.

Ao mesmo tempo, julgar se o próprio entendimento do texto está correto levanta o problema do contexto, do círculo hermenêutico, da relatividade do conjunto dos dados relevantes, da possível pertinência de investigações mais remotas e das limitações a ser colocadas no escopo da própria interpretação. Afirmar o que é considerado o entendimento correto do texto levanta a questão da 
verdadeira tarefa do exegeta, das categorias que ele deve empregar e da linguagem de que se deve valer.

Foi por meio desse método interpretativo de Lonergan que busquei realizar a tarefa de apresentar, de modo adequado, a contribuição de Mário Vieira de Mello sobre o que seria a ordem correta da alma em relação à ordem correta da sociedade com o fim de estabelecer um esboço, as linhas preliminares, de um projeto de democracia ética e sua relação com o conceito de uma educação da cultura, cujo princípio antropológico foi inspirado em Platão e descrito em $A$ República.

\section{VIDA E OBRA}

Mário Vieira de Mello nasceu na Inglaterra em 26 de maio de 1912, onde se encontrava seu pai no desempenho de missão oficial da Marinha. Educado no Brasil, em 1930 ingressa na Faculdade de Direito do Catete e passa a conviver no CAJU, Centro Acadêmico Jurídico Universitário, com futuras figuras de destaque da vida literária, política e acadêmica do Rio de Janeiro, tais como: Américo Lacombe, Antônio Gallotti, Gílson Amado, Thiers Martins Moreira, Plínio Doyle, Chermont de Miranda, Hélio Viana, Clóvis P. da Rocha, Octávio de Farias e San Tiago Dantas - estes dois últimos tornaramse incontestáveis lideranças. Para Vieira de Mello, a amizade com Octávio de Farias, um pouco mais velho, permitiu-lhe uma franca entrada numa família de escritores: o pai, Alberto de Faria, e seus cunhados, Afrânio Peixoto e Alceu Amoroso Lima.

Somado a esse grupo, vieram conviver com Vieira de Mello os colegas Álvaro Vieira Pinto, Tito Leme Lopes, Carlos Chagas Filho, Vinícius de Moraes, José Artur da Frota Moreira, Augusto de Rezende Rocha, Álvaro Penafiel e Almir de Castro. Nesse período, ao se lembrar de sua primeira juventude, quando começou a estudar filosofia, "Ato" (ergon, o efetivo) e "Potência" (dunamis) - distinção estabelecida por Aristóteles - eram as concepções com as quais se defrontou quando do seu primeiro contato intelectual com San Tiago Dantas. Confessa, porém, que "havia algo de demoníaco na concepção aristotélica de 'Ato' e 'Potência', algo de que seria extremamente perigoso acercar-se" (MELLO, 2001, p. 179).

Com o título de bacharel em direito nas mãos, Vieira de Mello custou a fixar-se na vida prática, sem qualquer vocação para a advocacia. Sua atração estava voltada para a leitura dos russos, Dostoievsky, Tolstoi, Gogol, Pushkin, Soloviev e Berdiaev; 
somada à sua fidelidade a Kierkegaard e a Nietzsche; seus estudos de Platão e de Sócrates; o impacto da Paidéia de Werner Jaeger, o seu Aristóteles bem como o de Whiteney Oates; a descoberta da história da filosofia russa de Zenkovsky - tudo isso contribuiu para que Vieira de Mello (2001, p. 178-179) formulasse, em tenra idade, um projeto intelectual de grande envergadura. Por isso, decidiu-se pela carreira diplomática, "compatível desde logo com o seu projeto cultural, com o recurso às fontes estrangeiras, numa época em que a carreira universitária, o estuário natural dum estudioso de sua marca, era objetivo a longo prazo e de limitadas perspectivas", esclarecia seu colega Almir de Castro (MELLO, 1993, p. 16).

Aprovado em concurso para a carreira diplomática em 1939, entre 1942 e 1958, serviu em postos diplomáticos em países europeus. No exercício de suas funções diplomáticas, como cônsul em Bordeaux, conselheiro antigo, pôde escrever o seu primeiro livro intitulado Desenvolvimento e Cultura, o Problema do Estetismo no Brasil, publicado em 1963. Nesse período, o Consulado em Bordeaux foi extinto, e Vieira de Mello ficou aguardando a sua transferência para outro posto, de 1958 a 1959, no Ministério, na época no Rio de Janeiro. O ministro das Relações Exteriores era o então amigo de juventude San Tiago Dantas, que havia implantado uma grande reforma no Itamaraty, em virtude da qual teve como efeito a necessidade de Vieira de Mello, embora fosse primeiro-secretário há mais de dez anos, servir sob as ordens de um funcionário mais jovem do que ele e que havia entrado no Itamaraty depois dele. Sentindo-se ultrajado, Vieira de Mello (2001, p. 181) fez

saber ao secretário-geral do Ministério das Relações Exteriores, embaixador Carlos Alfredo Bernardes, quais eram as minhas disposições. E, durante muito tempo, ficou-se sem saber o que fazer de mim porque eu não aceitava nenhum dos postos que me eram oferecidos. Não sei como não fui demitido. A situação só mudou quando San Tiago [Dantas] finalmente deixou o cargo. Com o novo ministro, Afonso Arinos de Mello Franco, o seu chefe de Gabinete, ministro Roberto Assumpção, conseguiu imediatamente a minha transferência para a Delegação do Brasil junto à Unesco. Seu chefe, o embaixador Paulo Carneiro, era um homem que eu admirava e de quem me tornei, no decorrer dos anos, íntimo amigo. Quanto ao Roberto Assumpção, sei que o que fez por mim foi por amizade; mas ele próprio talvez não se tenha dado conta do que significou para mim o seu gesto generoso: não só a solução de uma grave crise, como também o restabelecimento de um equilíbrio emocional perturbado por aquela agressão inesperada.

Comissionado no exterior, lá permaneceu até aposentar-se em 1974, encerrando a carreira, sucessivamente, como embaixador 
em Gana (África), Guatemala e Hungria. Desde então radicado em definitivo no Brasil, passou a participar mais extensamente do debate universitário, notadamente na Universidade de Brasília (UNB) e no Instituto de Estudos Políticos Econômicos e Sociais (IEPES), localizado no Rio de Janeiro. Como estudioso e pesquisador solitário, elaborou uma densa e profunda análise do problema da cultura no Brasil e da necessidade de nós, brasileiros, realizarmos uma assimilação verdadeira da autêntica tradição cultural europeia. Em seus livros, há o esboço de um pensamento alicerçado na liberdade interior e na transcendência, bases essenciais de uma cultura do futuro digna de uma civilização. Tal concepção filosófica encontra-se embasada num sólido conhecimento da filosofia clássica e contemporânea, da história antiga, de filologia e de história das religiões. Pouco antes de completar 94 anos, Mário Vieira de Mello faleceu, em 30 de março de 2006.

Nos escritos de Vieira de Mello (1963; 1985; 1986; 1993; 1994; 1996; 2001), está analisado e exposto como a Estrutura de Poder e a Estrutura de Cultura definiram - a partir de três noções chaves (quais sejam: as noções de bem, verdade e belo) - o conceito do que é o humanismo. Esses escritos (MELLO, 1963; 1985; 1986; 1993; 1994; 1996; 2001) revelam uma sincera e profunda definição do homem a partir da sua liberdade interna, que é a liberdade do animal que transcende sua natureza animal, cuja faina diuturna é "a vitória sobre si mesmo", numa crítica à liberdade externa, como a forma incitada por um agente exterior que, depois de destruir a ordem, a harmonia e o equilíbrio da alma humana - equilíbrio este criado por meio da homologia da ordem na alma do indivíduo e na sociedade -, realiza a instrumentalização dos instintos e das paixões do homem, de modo a que ele possa contribuir para o bom funcionamento da sociedade por meio do que se convencionou chamar de self-enlightened interest (o interesse próprio esclarecido).

Vieira de Mello (2001) procura confrontar o pensamento ético, voltado para perscrutar a liberdade íntima e moral do homem e analisar a conduta ética, dirigida para os valores superiores, com o pensamento científico-tecnológico do "homem curioso", inclinado à compreensão do mundo exterior, implícita ou explicitamente para dominá-lo. Em Sócrates e em Aristóteles, vê nosso autor os representantes paradigmáticos daquela e desta forma de pensamento. Em Sócrates, Vieira de Mello identifica a expressão mais exemplar, no curso de toda a história, de uma bem integrada racionalidade ética, que coloca a razão a serviço da prática da virtude. 
Em Aristóteles, vê a funesta origem da separação da razão da liberdade interior, convertendo a busca do "ser", em detrimento dos valores, na preocupação central da filosofia, o que iria favorecer a ciência e suas decorrências tecnológicas, em detrimento da ética, e a vontade de saber e de poder, em detrimento da virtude. Na sequência de Aristóteles, Descartes, Kant e Heidegger farão da filosofia uma busca do ser. Depois de Sócrates e Platão, somente Lutero, em parte, e Kierkegaard e Nietzsche, plenamente, voltaram a se ocupar da verdadeira liberdade, que é a liberdade interior, a liberdade moral, "que nada tem a ver com a liberdade de origem social" - como afirma Vieira de Mello. Como afirmou Sócrates, "o homem pode ser socialmente livre e interiormente escravo, como pode ser socialmente escravo e interiormente livre". Desta forma, Vieira de Mello revela qual é o "ser" do "homem curioso" que foi forjado a partir da filosofia aristotélica e chegou até hoje. Este "ser" visa compreender o mundo exterior para dominá-lo. E tal domínio encerra o projeto de ciência que, desvinculada de uma ética capaz de frear os instintos humanos, está causando a destruição da Natureza e incitando o lado mais instintivo do Homem, como se essa fosse a sua verdadeira liberdade.

No início de sua Metafísica, Aristóteles afirma que o desejo natural do homem é conhecer. Nada declara sobre a questão de ser ele ou desejar ser um homem livre. Toda sua filosofia está marcada por essa prioridade absoluta atribuída ao princípio do conhecimento. Mas o homem deseja inegavelmente ser livre, não apenas conhecer. O conhecimento é um meio, a liberdade, um fim. Essa é a lição da cultura clássica dos gregos, não a lição de Aristóteles. Para Mário Vieira de Mello (2001, p. 13), na "concepção de Sócrates, a economia moral do ser humano se traduz pela hegemonia da razão sobre as paixões e os instintos, mas isso não como uma expressão a serviço prestado ao conhecimento, mas como a expressão de um serviço prestado à liberdade".

A despeito de scholars norte-americanos e da Inglaterra (entre os quais há os nomes de Toynbee, Popper, Russel, Crossman) terem se permitido ser, no mínimo, reticentes em seu julgamento sobre as figuras de Sócrates e Platão, de numa reunião dos anos 1950 da Divisão do Pacífico da Sociedade Americana de Filosofia o seu presidente abrir a conferência com um discurso em que se referia à obra República como a "carta" filosófica original do fascismo; de Karl Popper, em seu A Sociedade Aberta e Seus Inimigos, qualificar que a República platônica foi a primeira tentativa teórica de retornar à original sociedade fechada, um passo para trás para recuperar a estática ordem perdida; creio, 
no entanto, que longe de serem inimigos da liberdade, Sócrates e Platão foram, ao contrário, os seus descobridores, pois só quando surge na história do homem a noção de liberdade interior, podese dizer ter o verdadeiro conceito de liberdade iniciado realmente sua trajetória. E se Platão revelou-se contra a liberdade exterior da democracia ateniense, foi justamente porque essa liberdade exterior sufocava a liberdade interior que estava querendo suscitar.

O homem contemporâneo tem dificuldade em assimilar essa noção de liberdade interior. Pois o homem contemporâneo é ávido de liberdade - liberdade de locomoção, liberdade de expressão, liberdade de reunião, liberdade de conquista, liberdade do mais forte, liberdade do poder -; há de se interrogar que num mundo assim, em que a compreensão da liberdade que tem o homem não vai além dessa dimensão da liberdade animal, fica difícil imaginar como as sociedades possam se estruturar, como um princípio de ordem possa regular a convivência dos homens.

Como, então, evitar que os homens se "entredestruam" em ondas de violência cada vez mais avassaladoras? De imediato, a perspectiva que se oferece ao homem é a de que somente um Estado hostil - totalitário ou que, por outras formas, desrespeite a liberdade interior do homem, instrumentalizando as paixões - é capaz de reprimir ou de domesticar. Contra esse fenômeno, nos planos do legislador da sociedade, há pretensão de intervir por meio da educação no estado de desordem da alma humana? Existe, como projeto social, o estabelecimento de um estado de coisas que inclua uma séria formação moral do ser humano?

A obra do filósofo Vieira de Mello nos permite encaminhar respostas a essas perguntas, ao vislumbrar que, nos planos do legislador da sociedade democrática igualitária, pretende-se intervir no estado de desordem da alma humana, mas não para substituir a desordem pela ordem, e sim para "aproveitar-se da desordem e mantê-la como condição indispensável para a obtenção de fins sociais considerados desejáveis" (MELLO, 1996, p. 321-322). Ainda de acordo com ele, do ponto de vista da educação, o legislador está se intrometendo nesta área, porém de maneira insuportável.

A área da educação, o legislador da sociedade democrática igualitária deveria respeitá-la, "porque nela se realizam objetivos superiores ao interesse do Estado. O legislador pode e deve legislar em matéria educacional, mas sempre respeitando os objetivos superiores da educação - e um deles, evidentemente, é o aperfeiçoamento moral do indivíduo" (MELLO, 1996, p. 322). Mas não mediante a prática do princípio do self-enlightened interest pela democracia igualitária. 
Baseando-se no estudo de Eric Voegelin (1975), para Vieira de Mello, o problema está no fato de que a democracia igualitária reconhece o estado de desordem em que vive a alma humana, mas mesmo assim, de forma fria e calculada, realiza a aceitação desse estado de desordem sem nenhum pensamento de que seria preciso fazer algo para melhorá-lo. A ideia demoníaca é que se aproveita desse estado de desordem para realizar certos objetivos sociais que arbitrariamente são considerados estimáveis, especialmente visando contribuir para o desenvolvimento econômico da sociedade a que pertence.

Em sua contraposição, Vieira de Mello considera que há como optarmos por uma forma de convivência humana em que os homens sejam interiormente livres - interiormente livres com uma liberdade voltada para a transcendência - cujo mundo seja produto de uma elaboração racional, com base emocional e com sua gênese numa experiência histórica autêntica, compartilhada por toda uma comunidade.

\section{A IDEIA DE LIBERDADE MORAL COMO IGUAL À DE LIBERDADE INTERIOR}

No século XX, a filosofia clássica recuperou uma boa parte de seu prestígio, e isso se deve aos trabalhos em filologia clássica de Werner Jaeger, Paul Friedländer, Bruno Snell, Whitney J. Oates, Eduard Fraenkel. M. S. Silk, Hans-Georg Gadamer e, especialmente, às investigações do filósofo Eric Voegelin (1901-1985), cuja obra foi trazer elementos para fortalecer a ideia de que a filosofia clássica era uma das grandes fontes, talvez a maior fonte de energias espirituais que alimentam ainda hoje a humanidade. A partir dos últimos estudos de Max Weber em Wissenschft und Politik (Ciência e Política), com destaque à sua distinção entre Gesinnungsethik (ética da intenção) e Verantwortungsethik (ética da responsabilidade), associada ao problema de ele encontrar um sentido racional no curso da história, Eric Voegelin se enveredou pelo estudo comparado da civilização - não apenas da civilização moderna, mas também da medieval e antiga, e não apenas do Ocidente, mas também do Oriente Próximo e do Extremo Oriente - para mostrar que a história não tem um eidos (essência) definido, porque ela está em uma estrutura aberta dentro do fluxo da eternidade. No prefácio de Israel e a revelação, Voegelin (2009a, p. 27) afirma que a "ordem da história surge da história da ordem. Toda sociedade vê-se encarregada da tarefa de, sob suas condições concretas, criar uma ordem que dote de significado o fato de sua existência em termos dos fins divinos e humanos". 
Essa descoberta está no eixo de seu tratado Ordem e História (2009a; 2009b; 2009c; 2010a; 2010b). Por meio dessa visão histórico-filosófica, Voegelin também mostra que o homem tem uma inabilidade em suportar a tensão existencial ou incerteza com respeito ao futuro, o que leva o homem à tentação de criar ilusões intencionais, ou mitologias que querem se afirmar como "científicas", transferindo expectativas absolutas para factíveis estados perfeitos ou utópicos. Tais ilusões, conclui, só podem ser contrapostas por maduro ceticismo, que é condição para a verdadeira construção da ordem da alma, e com capacidade para realizar a verdadeira compreensão dos problemas da democracia, da liberdade, da ordem e da justiça (SILVA, 1985, p. 118).

Ao acompanhar esse empenho de Eric Voegelin de pesquisar uma ordem na História, cuja investigação pressupôs a convicção de que a História, se vista como simples desenrolar de acontecimentos sociais, políticos, econômicos e mesmo filosóficos, ela não possui antenas para captar a essência do drama espiritual que constitui a presença do Homem sobre a Terra, Vieira de Mello (1986, p. 254) vislumbrou que a História não está somente subordinada a uma imanência, e sim que a "História é uma forma do existir humano que exprime uma situação em que justamente o Homem se abriu à transcendência".

$\mathrm{Na}$ crítica à tentação de reduzir a realidade humana à moldura unidimensional, presa à imanência, Vieira de Mello segue a investigação de Voegelin. Conforme este último autor, entre 800 e 300 a.C. ocorreu o que ele denominou de "abertura da alma", quando algo novo aparece na história e não apenas no Ocidente: a descoberta da verdade como independente da sociedade. Assim, desde os seus primórdios, filosofar é assumir uma posição independente ou crítica, questionando e resistindo à verdade oficial da sociedade.

Foi nesse ambiente que nasceu a crítica socrático-platônica à democracia ateniense. Sócrates e Platão criticaram a Democracia de sua Cidade e de seu tempo, porque fizeram uma distinção essencial entre dois tipos de liberdade - uma dada pela democracia e outra, pela educação. Para além dessa crítica, o que Sócrates realizou foi trazer para nós uma nova dimensão: a dimensão da liberdade espiritual. De acordo com Vieira de Mello (1986, p. 108):

Sócrates foi o primeiro homem que fez da liberdade um problema moral. Antes dele nunca se havia questionado o sistema social que divide os habitantes de uma Cidade em duas classes, os escravos e os homens livres. O próprio Sócrates não o fez. Mas ao transferir essa divisão para o interior do mundo moral, 
Sócrates abalou profundamente os alicerces da estrutura social e política dentro da qual transcorreu sua vida. Uma nova ideia de liberdade surgiu, a ideia de liberdade espiritual que precisamente não existia na democracia de Péricles. Era livre, segundo Sócrates, o homem em quem a razão dominasse ou controlasse os instintos. Era escravo aquele em quem a razão se deixasse dominar pelos instintos. Qual era a consequência dessa transferência? Era que, segundo Sócrates, o homem podia ser livre social e politicamente e ser ao mesmo tempo eticamente um escravo. Ou inversamente: o homem podia ser social e politicamente um escravo e ao mesmo tempo ser, eticamente, livre.

Ou seja, ao transferir para o interior do mundo moral a distinção entre escravos e homens livres, Sócrates trouxe para nós uma nova dimensão: a dimensão da liberdade espiritual. E a morte de Sócrates pela democracia ateniense indicou para Platão a necessidade de uma reestruturação completa do Estado, a partir do indivíduo ético, pois havia mostrado que qualquer forma possível de Estado então existente entraria em conflito com um indivíduo que representava o que de melhor havia até então produzido a espécie humana. De sorte que a morte de Sócrates não foi determinada por um conflito entre as leis do Estado e os direitos do indivíduo, ele não foi, portanto, só vítima - ele foi, sobretudo, origem, causa desse conflito de que também foi vítima. "Nisso vai uma boa diferença", argumenta Vieira de Mello (1986, p. 115).

E Sócrates surge justamente na época em o Estado aristocrático desaparece nos centros mais importantes da Grécia e com ele a transmissão hereditária das qualidades de estadistas, o que faz aparecer para os helenos o problema de como realizar essa transmissão por via não hereditária. Concomitantemente ao aparecimento da democracia, tem lugar o movimento educacional dos Sofistas, cujos fins visavam assegurar novos meios de formação do estadista. Intimamente ligados à Democracia, os Sofistas se apresentaram para substituir o Estado democrático quando este se mostrou incapaz de satisfazer a necessidade de educar o estadista e por meio dele educar o povo. De acordo com Vieira de Mello, para Sócrates os educadores sofistas, ao pretender substituir o Estado na função educacional, mostraram, no entanto, que não eram estadistas,

pois a educação que ofereciam não visava tornar os homens melhores. Sócrates reivindicava para si o privilégio de ser o único Educador e por via de consequência o único estadista de seu tempo. Como Educador procurava descobrir a verdade da alma humana para discipliná-la e organizá-la de modo a torná-la cada vez melhor. Como estadista procurava mostrar que as raízes de qualquer constituição da sociedade estavam plantadas no interior da alma individual do homem. (MELLO, 1986, p. 125) 
A partir de Sócrates, então, Platão disse que a arte do estadista consiste em educar os homens, e essa afirmação deve ser acrescida da proposta que lhe é intrínseca: educar os homens para torná-los melhores. Assim, o Estado educacional platônico não é o Estado que educa com o objetivo de integrar os indivíduos membros da coletividade no seu projeto social; não é o Estado que faz da educação um instrumento para servir a seus fins; é, ao contrário, um Estado que se faz instrumento para servir aos fins da educação.

A concepção platônica do Estado era o mesmo Estado que procurava Sócrates, um Estado que pudesse ter também uma função moral e educativa, pois há uma homologia entre Estado e indivíduo. O ponto de aplicação do seu esforço é o Estado no indivíduo, no interior da alma individual. Para Vieira de Mello, a intuição de Platão de conceber o Estado dentro do homem, no interior da alma humana, está associada à convicção de Sócrates de que o Estado foi feito para tornar os indivíduos melhores. Dessa forma, entende-se que Platão criticou não a Democracia ateniense considerada como organização do Estado, mas o Estado democrático dentro do homem, ou antes, a alma democrática. E não somente a crítica recai sobre a democracia. De forma equânime, a crítica é endereçada a todas as formas de constituição política - e elas são realizadas unicamente do ponto de vista da educação que puderam dar ao homem.

Mas como conseguir essa capacidade para nos tornarmos eticamente livre? Afinal, razão e liberdade não são pares antitéticos? Parece-nos que a liberdade é eruptiva e inimiga da ética, como também nos parece que a ética é restritiva e cerceadora das paixões humanas. Em outras palavras, como conseguir, numa sociedade, que seus cidadãos sejam, ao mesmo tempo, éticos e livres? Para encaminharmos resposta a essas questões, acompanhemos o ideal, por meio da paideia, da formação da autonomia ética do indivíduo.

\section{A RAZÃO COMO DINÂMICA PEDAGÓGICA}

Vieira de Mello chama-nos a atenção para as palavras racionalidade e liberdade; célebres no mundo de hoje, são dois eixos em torno dos quais giram o orgulho, a satisfação própria e a altivez da civilização contemporânea. Assim pensamos nós. Mas somos de fato racionais e livres? É tão comum assim vermos essas duas qualidades conjugadas na estrutura moral no homem ocidental? A que cifras chegaremos se quisermos juntar os homens que reúnem as duas qualidades? "A verdade é que para nós" 
- assevera Vieira de Mello (1986, p. 156) - "a racionalidade parece estar imediatamente associada a um certo determinismo, a algo que representa a negação da liberdade; e essa parece estar intimamente associada a uma certa irracionalidade".

Mesmo assim, presume-se que racionalidade e liberdade correspondem a realidades que co-habitam sem dificuldade a estrutura da alma humana. Parece haver alguma pretensão no fato de que o homem ocidental se considere capaz de realizar essa proeza; e aprecia-se que a proeza é assumida sem que haja sido feito o menor esforço para que ela seja executada. Com efeito, há de se indagar:

[...] que fez o homem ocidental para evitar que o seu racionalismo excessivo transformasse sua consciência em algo ressecado, esquemático, desprovido de imaginação e sensibilidade? Que fez ele para evitar que suas fantasias, desregramentos e libertinagens a transformasse em algo de totalmente distorcido e indisciplinado, incapaz de qualquer tipo de previsão e ordenamento? Aparentemente ele não se deu conta de que racionalidade e liberdade são condições da vida humana extremamente positivas, mas que só o são quando estão inseridas na estrutura da alma humana de uma certa maneira, que só o olhar vigilante do pedagogo competente saberá determinar. (MELLO, 1986, p. 156)

E Platão - para Vieira de Mello (1986, p.157) - “foi e continua sendo o pedagogo mais competente a quem nos devemos referir se quisermos ter uma visão não distorcida da estrutura da alma humana".

No entanto, os modernos, levianamente, arbitrariamente, sem o menor tipo de consideração quanto aos cuidados a tomar no exercício de uma pedagogia competente, inventaram coisas como a "razão instrumental" ou a "liberdade desengajada". O resultado foi pernicioso, chegando, hoje em dia, a proclamar-se da forma mais banal que os métodos da ciência devem ser aplicados em todos os ramos do conhecimento. Para Vieira de Mello, a convicção de que a razão pode ser desengajada, que nunca se associa à liberdade para estruturar a alma humana, teve como resultado parar, acabar, pôr termo ao processo educacional que pedagogos competentes haviam julgado indispensáveis à formação moral e intelectual do ser humano. Não que a razão tenha deixado de intervir - esclarece Vieira de Mello (1986, p.159):

[...] de modo ou de outro, sempre não educacionalmente, na estrutura da alma humana. A razão era desengajada no que se referia à ação educacional que, eventualmente, pudesse ela própria exercer; mas não era no que se referia à ação do legislador, por exemplo, que quisesse intervir na psicologia humana, instrumentalizando paixões, atiçando o egoísmo humano de modo a torná-lo um instrumento na obtenção de certos fins considerados socialmente desejáveis. 
Essa é a grande contribuição da ideologia liberal dada por Locke ao mundo moderno. A filosofia oportunística de Locke permitiu e incentivou que o Estado se tornasse o servidor das paixões mais baixas do indivíduo. A revelação realizada por Eric Voegelin (1975) do lado obscuro das teorias transparentes - especialmente a luminosa teoria da democracia igualitária - , mostra-nos como a análise das paixões humanas em Pascal se alia à análise do egoísmo em Helvetius para, nas mãos de Locke, se transformar no princípio perverso do self-enlightened interest.

Por meio desse tão admirado "realismo", a razão ética, a razão capaz de controlar as paixões humanas, não encontra terreno favorável na alma do indivíduo que não está unido interiormente ao Estado sob cuja jurisdição deve viver; não pode tampouco se desenvolver dentro de uma ordem social para a qual não contribui a ordem individual de cada um de seus membros. A razão ética é produzida ao se estabelecer o relacionamento entre uma ordem e outra; não existe uma ética social e outra individual; essas são simples produtos perversos da distorção de um fenômeno único que é a realização ética do indivíduo dentro do seu contexto social - avalia Vieira de Mello (1996).

Com efeito, a então denominada "razão desengajada" significa uma razão que não tem o menor compromisso com o homem. Faça ele o que quiser, tenha o destino que a sorte lhe reservar, essa razão não intervém. Para o ser humano, a utilidade dessa razão desengajada é não a conquista de si mesmo, mas a conquista física do universo. A razão desengajada não reconhece uma ordem nesse universo a que deva se articular - não reconhece, em consequência, uma ordem na alma do homem que deva respeitar. Os resultados de sua atividade não se traduzem em termos de ordem nessa alma, e sim em termos de eficiência e poder sobre o mundo físico. A razão desengajada dá ao homem não mais poder sobre si mesmo, donde resultariam autonomia e liberdade humana, mas maior eficácia, maior poder na utilização das forças do universo físico, o que lhe dá maior conforto, maiores facilidades de comunicação e de transporte e, de uma maneira geral, maiores facilidades no atendimento das necessidades ligadas à sua existência material.

A razão desengajada desdenha a racionalidade clássica dos gregos, talvez porque esta última não seja compreendida. Em sua defesa do humanismo - o humanismo que Vieira de Mello acredita ter se originado de circunstâncias muito especiais; e que certamente nunca mais se reproduzirão - o levou a destacar: 
A razão humana é um instinto e, como tal, necessariamente engajada, em virtude mesmo de sua essência. Engajada como são os demais instintos do homem. Seria cômico dizer que o ódio, o amor, a prudência, a coragem não são instintos engajados. A razão é um instinto e, como as demais faculdades da alma humana, está necessariamente engajada. A única coisa que distingue a razão do instinto propriamente dito é que este último é imediatista, cego quanto ao futuro, não vê senão o presente, ao passo que aquela vê mais longe, é capaz de planejar e calcular. Quando Kant escreveu a Crítica da razão pura criou-se no mundo filosófico a impressão de que a razão era uma entidade, uma estrutura, dentro da qual existia um departamento onde se fabricavam as sínteses, a priori, das formas do espaço e do tempo, antes de receber do mundo exterior o dado empírico que era então apresentado ao entendimento sob forma de fenômeno. Tudo isso parecia uma maravilhosa engenharia que contribuía enormemente para fazer da razão pura uma respeitável entidade, uma verdadeira usina. Tudo isso parecia de uma luminosidade extraordinária, mas nos fazia perder de vista o fato de que a razão é muito mais do que um instrumento de conhecimento - de que a razão é uma faculdade que tem muito a ver com o drama, ou, se se quiser, com a tragédia de nossa existência. (MELLO, 1996, p. 226)

Dessa ideia do que é racionalidade, de que esta só pode ser formada por meio da consideração do que nos é oferecido com o exemplo grego - e mais: que é inútil tentar definir o que é racionalidade fora deste exemplo - para Vieira de Mello, então, a ideia de que a cultura do Ocidente fosse uma cultura racionalista sempre lhe pareceu uma ilusão. Já em seu primeiro livro, Desenvolvimento e cultura: o problema do estetismo no Brasil, ele descreveu a Europa, a partir do século XVI, dividida, dilacerada entre duas tradições antagônicas: a tradição estética do Renascimento italiano e a tradição ética da Reforma de Lutero. Nesse livro, ele mencionou que o racionalismo francês deve ser entendido como um subproduto do estetismo. Como forma de estetismo, o racionalismo francês foi uma nova forma de rejeição da cultura medieval, uma variedade do humanismo renascentista. As linhas mestras da cultura ocidental a partir do século XVI se definem em função das duas tradições, a ética e a estética, e do conflito que se estabeleceu entre elas. O desenvolvimento científico do Ocidente, por si só, não poderia justificar a noção de que sua cultura é racionalista. Identificar ciência e racionalidade da cultura é tentar identificar a parte com o todo. A ciência ocidental, apesar do enorme desenvolvimento que teve, apesar da extraordinária tecnologia a que deu origem, continua a ser parte, e somente parte, da cultura ocidental - se um dia ela representar o todo, isso significaria, simplesmente, que a cultura ocidental teria desaparecido - assegura Vieira de Mello. 
Assim como os pares de duas tradições, a ética e a estética, há também o tema da tensão entre poder e cultura. Ainda em sua defesa do humanismo, Vieira de Mello considera crucial expor que o problema da liberdade é infinitamente mais importante do que o problema do poder. Por isso, a sua reflexão recai sobre a liberdade interior e moral do homem e de como a sociedade está organizada em torno das estruturas de poder em detrimento das estruturas de cultura. Em outras palavras, Vieira de Mello absorve os ensinamentos de Sócrates-Platão para os quais a politeia deve estar subordinada à paideia. É somente desta maneira que existiria a liberdade interior e moral expressa na correlação entre a organização anímica e sua exteriorização na sociedade, pois "na cidade há as mesmas partes que há na alma de cada um e são iguais a ela em número" (PLATÃO, A República, Livro IV - 441c).

Em oposição à tradição filosófica humanista presente em Sócrates-Platão, para Vieira de Mello foi Aristóteles quem iniciou um modo de pensar a liberdade como uma faculdade de escolha - expressão de um serviço prestado ao conhecimento - que desmantelou aquela outra concepção de liberdade que se traduz como hegemonia da razão sobre as paixões e os instintos.

Com o intuito de recuperar as qualidades socráticas que escaparam à percepção do homem formado no seio da cultura do Ocidente, em $O$ conceito de uma educação da cultura, Vieira de Mello deu algumas indicações sobre isso no capítulo intitulado "O fenômeno da conversão na filosofia platônica/Aristóteles e a pergunta socrática sobre a virtude". Neste capítulo, ao estudar o tratamento dado por Aristóteles à pergunta socrática "A virtude pode ser ensinada?", nosso autor procurou mostrar como Aristóteles, tentando refutar a tese socrática de que virtude é conhecimento, fora obrigado a entrar num círculo vicioso do qual só pudera escapar usando estratagemas e distinções capciosas. O problema - esclarece Vieira de Mello:

[...] é que o projeto de Aristóteles de realizar uma síntese entre as duas tradições que tinha atrás de si - a tradição cosmológica dos Iônicos e a tradição humanista de Sócrates e Platão - só poderia ser realizado através da ação do filósofo educador capaz da conversão dialética, o que ele peremptoriamente recusou a fazer. Só essa intervenção do filósofo educador poderia levá-lo, dentro de um projeto, da imanência à transcendência. Sem a conversão, como poderia ele realizar uma tal síntese de maneira orgânica, criando dentro do seu projeto uma verdadeira unidade? Aristóteles ignorou a conversão. Optou por uma síntese artificial que deveria, mais cedo ou mais tarde, fazer sentir sua artificialidade: tentou unir ciência iônica com o humanismo de Sócrates e Platão. Com isso sofreu a ciência, que foi obrigada a mais tarde, com Descartes, a rejeitar o humanismo para 
preservar a sua integridade; e sofreu também o humanismo, que teve sempre, a partir de Aristóteles, suas fontes contaminadas pelas águas impuras da ciência. Não há a menor dúvida de que a obra aristotélica foi um monumento esplêndido de construção lógica, ontológica e cosmológica; mas ele foi também um muro alto, uma barreira sólida, um obstáculo intransponível, impedindo que as ideias de Sócrates, aparentemente simples mas na realidade profundas, exercessem sobre o Ocidente a influência benéfica e altamente renovadora que exerceram sobre Platão e um certo número de pessoas que procuraram um convívio em busca de uma bússola, de um roteiro capaz de orientá-los na desordem e no caos que iam, pouco a pouco, se formando naquela época de crise e confrontos, angústias e dificuldades. (MELLO, 1996, p. 203-204)

Nos livros O conceito de uma educação da cultura (1986) e O cidadão (1994), Vieira de Mello analisou que o problema da liberdade tinha dois caminhos a ser pensados: uma liberdade derivada de ideias de cultura, e uma liberdade resultante de ideias de poder. Ao analisar a existência de dois tipos de liberdade, uma interior ou espiritual, e outra exterior ou natural, manifestadas na história político-cultural da humanidade, ele distinguia uma liberdade derivada das realidades de cultura que tinha expressão máxima a formulação do ideal clássico na sociedade ateniense do século IV antes de Cristo, a que se dá o nome de humanismo; e uma liberdade derivada das realidades do poder que tinha como encarnação mais evidente a sociedade dos Estados Unidos, que emergiu dos sucessos da revolução americana. Mas, às vezes, a liberdade oriunda da ideia de poder pode se confundir com a liberdade produzida no seio da cultura. A razão disso, assevera Vieira de Mello, é, naturalmente, a semelhança que pode existir entre uma coisa e sua imitação, porque cultura é uma continuação da vida; poder é um seu ingrediente ou imitação.

E mais: a cultura é superior ao poder porque nasce do conflito do poder consigo mesmo. Esse tema da tensão entre poder e cultura foi desenvolvido por Nietzsche, e é examinado por Vieira de Mello (1993). Para este autor, Nietzsche é um educador tão forte quanto Sócrates e Platão. O que distingue esses filósofos de todos os outros que o sucederam foi terem eles dado à educação uma posição central no processo de reflexão filosófica.

O humanismo não é um ideal, é um acontecimento espiritual: a descoberta do homem de sua própria alma - acontecimento incomparável, que nos foi descrito por Nietzsche em sua Genealogia da Moral (1999). O homem primitivo, feroz, cruel, predador, vivia, continuamente, em guerra, em invasões, em conquistas e atropelos, num extermínio recíproco, enfim. A espécie humana teria, talvez, desaparecido da face da terra se os instintos cruéis do homem 
se tivessem apenas exercido contra o inimigo que o ameaçava. Mas aconteceu de repente uma coisa extraordinária. Com a mesma crueldade e ferocidade com que atacavam o inimigo, os instintos do homem se voltaram contra ele próprio, e um processo de interiorização se iniciou em que a vítima era o próprio agressor. Assim se formou a alma que, de acordo com Nietzsche, fez do homem um animal doente, mas, inesperadamente, um animal "interessante", que introduzia no mundo um espaço novo, um espaço interior, o espaço em que coisas maravilhosas se produziam e em que o homem se tornava verdadeiramente digno de contemplação dos deuses. Esse processo foi analisado por Mário Vieira de Mello em Nietzsche, o Sócrates dos nossos tempos (1993). Nele foram expostas duas descobertas de suma importância:

[...] a descoberta da alma e a descoberta da liberdade, etapas fundamentais na constituição do que hoje chamamos de civilização ocidental. Não foi a ciência nem a racionalidade, se estendermos por isso as operações da razão desengajada, o que determinou o perfil absolutamente singular de nossa cultura - foi, ao contrário, a alma interiorizada e o processo dialético através do qual razão e liberdade criaram o mundo espiritual do homem. (MELLO, 1996, p. 328)

Mário Vieira de Mello foi, na plena acepção da palavra, um educador da alma e do Estado. Apesar de sua obra, no entanto, não tem sido suficientemente reconhecida a centralidade da educação no processo filosófico, pois essa centralidade seria, sem dúvida, a solução para o difícil problema das relações entre razão e liberdade. Essa sugestão, ao que nos parece, está sendo recebida com um sentimento de estranheza, para não dizer de uma total indiferença. Talvez porque o conceito de uma educação da cultura com referência à criação de um espírito ético traga consigo a ideia de ordem cujo significado é, no mais das vezes, mal-interpretado. Pensa-se em ordem na sociedade do mesmo modo em que o militar pensa em disciplina na corporação a que pertence; ou ordem como equivalente à restrição à liberdade do indivíduo. Ordem significaria, sim, no sentido atribuído por Mário Vieira de Mello, dar ao indivíduo a possibilidade de enriquecer sua própria substância humana por meio do convívio com os outros indivíduos que fazem parte da comunidade a que pertence. A ordem então seria enriquecedora, não limitadora. Essa defesa do humanismo e da convicção de que cultura e humanismo são noções equivalentes, cujo ato básico da moralidade - o domínio das paixões pela razão humana - é uma manifestação da cultura porque se busca construir uma homologia da ordem correta da alma em relação à ordem correta da sociedade. Assim, o homem não é uma realidade, o homem 
é uma possibilidade. Essa ideia de que o homem é uma possibilidade está associada à ideia de que a educação deva ter uma posição central na vida espiritual do homem. Isso, no entanto, é aterrorizador para o homem contemporâneo que não quer se engajar em nenhum plano que o faça dispensar a sua individualidade e o seu descompromisso. Além disso, soa-lhe estrambótica a concepção de que é "impossível desculpar as consequências maléficas de atos morais pela moralidade ou nobreza das intenções do agente. A intenção moralizadora não justifica a imoralidade da ação" (VOEGELIN, 2008, p. 31-32).

\section{CONSIDERAÇÕES FINAIS}

É difícil reconhecer a ordem democrática contemporânea como uma ordem social verdadeira. A dificuldade com a ordem democrática contemporânea é que ela não é autossuficiente, não deriva de um centro organizador da vida plenamente autônomo e, a partir de sua própria interioridade, gerador de estruturas. A ordem democrática contemporânea é, em si mesma, uma estrutura exteriorizada, sem vínculos de espécie nenhuma com qualquer tipo de interioridade.

Conforme exposto, a obra do filósofo Mário Vieira de Mello (1912-2006) nos permite perceber que a democracia pode ser definida pelos seus aspectos positivos, ao defender que o núcleo sólido e indestrutível da democracia é a autonomia ética do indivíduo. E a existência de um ethos autônomo no indivíduo só é possível se admitirmos a existência do Estado dentro dele. É da interiorização do Estado no indivíduo que decorre a autonomização do ethos individual.

E, para Vieira de Mello, foi Platão quem intuiu que ética e política estão fundidas e os dois termos se equivalem. Por isso, continua ele a expor, não há, pois, por que estranhar a afirmação de que a concepção ética que domina o mundo moderno e contemporâneo - com referência à concepção da autonomia ética do indivíduo - deriva diretamente de uma concepção política que representava quando surgiu uma grande inovação: a concepção segundo a qual o Estado existe não apenas como forma objetiva e exterior, como estrutura externa e organização de poder; mas que existe também no interior da alma humana, e que essa segunda forma de existência tem precedência sobre a outra. É essa nova concepção política que permitiu que fosse o indivíduo considerado como microcosmo dotado de autonomia. 
Foi Platão, então, por meio da filosofia de Sócrates, que conseguiu encontrar o processo em virtude do qual poderiam ser reunidas, num movimento, as duas forças principais da alma humana - a razão e a liberdade. Esse processo, Platão chamou-o de dialética, cujo movimento, alicerçado pela educação para a consecução do projeto de instaurar uma democracia ética, cria e estabelece a ordem na alma do indivíduo e na sociedade.

Como um elixir, esse insight inspirado em Platão induz Mário Vieira de Mello a acreditar na necessidade de uma cultura ética como preliminar para o estabelecimento, no Brasil, de um verdadeiro regime democrático. E que é impossível fazer da educação um trampolim para a democracia, caso antes não seja feito um estágio no patamar da cultura. Essa cultura, pois, deverá ter um caráter acentuadamente ético e baseado em autores cuja reflexão ética atingiu os seus níveis mais elevados - como Sócrates e Platão, Lutero, em parte, Kierkegaard, Nietzsche, Eric Voegelin.

Tem de ser suficientemente apreciado que a relação existente entre democracia e cultura é uma relação de conflito. Afinal, hoje, educação é um conceito ligado essencialmente ao mundo do espírito, enquanto democracia é uma noção associada, pelos seus aspectos estruturais, ao mundo do poder. Para Mário Vieira de Mello, é somente a partir dessa intuição fundamental que se pode elaborar uma concepção de democracia que supere essa oposição inicial, por meio da assimilação, na medida do possível, e incorporação ao ideal democrático da noção de uma liberdade interior, que essa sim, representa com autenticidade o mundo do espírito. Tal ideal, oriundo da cultura, é superior, ou seja, a cultura é superior ao poder porque ela representa a vitória do poder sobre si mesmo.

\section{REFERÊNCIAS}

LONERGAN, Bernard. Método em Teologia. São Paulo: É Realizações, 2013 [1971].

MELLO, Mário Vieira de. Desenvolvimento e Cultura. O problema do estetismo no Brasil. São Paulo: Companhia Editora Nacional, 1963.

- Nietassche. Rio de Janeiro: Paz e Terra; Instituto de Estudos Políticos e Sociais, 1985.

. O conceito de uma educação da cultura: com referência ao estetismo e à criação de um espírito ético no Brasil. Rio de Janeiro: Paz e Terra, 1986.

. Nietzsche: o Sócrates de nossos tempos. São Paulo: Edusp, 1993.

. O cidadão: ensaio de política filosófica. Rio de Janeiro: Topbooks, 1994. 
O bumanista: a ordem na alma do indivíduo e na sociedade. Rio de Janeiro: Topbooks, 1996.

- O homem curioso: o problema da exterioridade na filosofia de Aristóteles. Rio de Janeiro: Paz e Terra, 2001.

NIETZSCHE, Friedrich. Zur Genealogie der Moral. Eine Streitschrift. Berlin: Goldmann, 1999. PLATÃO. A república: [ou sobre a justiça, diálogo político]. Trad. Anna Lia Amaral Almeida Prado; revisão técnica e introdução Roberto Bolzani Filho. São Paulo: Martins Fontes, 2006. Livro IV - 441c.

SILVA, Nelson Lehman da, A religião civil do estado moderno. Brasília: Thesaurus, 1983.

VOEGELIN, Eric. From enlightenment to revolution. Durham: Duke University Press, 1975.

. Reflexões autobiográficas. Trad. Maria Inês de Carvalho. São Paulo: È Realizações, 2008. Introdução e edição de texto de Ellis Sandoz. Notas de Martim Vasques da Cunha

a. Israel e a revelação. Trad. Cecília Camargo Bartalotti. São Paulo: Edições Loyola, 2009 Res. Tec. Marcelo Perine. [Ordem e História, v. 1].

b. O mundo da pólis. Trad. Luciana Pudenzi. São Paulo: Edições Loyola, 2009. Res. Tec. Marcelo Perine [Ordem e História, v. 2].

c. Platão e Aristóteles. Trad. Cecília Camargo Bartalotti. São Paulo: Edições Loyola, 2009. Res. Tec. Marcelo Perine [Ordem e História, v. 3].

d. A era ecumênica. Trad. Edson Bini. São Paulo: Edições Loyola, 2010. Res. Tec. Marcelo Perine. [Ordem e História, v. 4].

e. Em busca da ordem. Trad. Luciana Pudenzi. São Paulo, Edições Loyola, 2010. Res.

Tec. Marcelo Perine. [Ordem e História, v. 5].

Recebido: $18 / 11 / 2013$

Aprovado: 29/05/2014

Contato:

PUC Campinas

Programa de Pós-Graduação em Educação

Rod Dom Pedro I - Km 136

Parque das Universidades

Campinas | SP | Brasil

CEP 13.086-900 